\section{Failure Analysis under Electric Lights: Growth and Yield of Sweetpotato in Response to 14 Days of Prolonged Darkness}

\author{
Desmond G. Mortley ${ }^{1}$ \\ Center for Food and Environmental Systems for Human Exploration of Space \\ and G. W. Carver Agricultural Experiment Station, Tuskegee University, \\ Tuskegee, AL 36088
}

Douglas R. Hileman

Department of Biology, Tuskegee University, Tuskegee, AL 36088

\section{Conrad K. Bonsi, Walter A. Hill, and Carlton E. Morris \\ Center for Food and Environmental Systems for Human Exploration of Space and G.W. Carver Agricultural Experiment Station, Tuskegee University, Tuskegee, AL 36088}

Additional index words. Ipomoea batatas, nutrient film technique, interrupted light, controlled environment

\begin{abstract}
Two sweetpotato [Ipomoea batatas (L.) Lam] genotypes (TU-82-155 and NCC58) were grown hydroponically and subjected to a temporary loss of lighting in the form of 14 days of prolonged darkness compared with a lighted control under standard daily light periods to determine the impact on growth responses and storage root yield. Vine cuttings of both genotypes were grown in rectangular channels. At 65 days after planting, lights were turned off in the treatment chambers and replaced by a single incandescent lamp, providing between 7 and $10 \mu \mathrm{mol} \cdot \mathrm{m}^{-2} \cdot \mathrm{s}^{-1}$ photosynthetic photon flux $(P P F)$ for 18 hours, and the temperature lowered from $28 / 22{ }^{\circ} \mathrm{C}$ light/dark, to a constant $20^{\circ} \mathrm{C}$. Plants remained under these conditions for 14 days after which the original light level was restored. Growth chamber conditions predark included, a PPF mean provided by 400-W metal halide lamps, of $600 \pm 25 \mu \mathrm{mol} \cdot \mathrm{m}^{-2} \cdot \mathrm{s}^{-1}$, an 18-hour light/6-hour dark cycle and a relative humidity of $70 \% \pm 5 \%$. The nutrient solution used was a modified halfHoagland with $\mathrm{pH}$ and electrical conductivity (EC) maintained between 5.5-6.0 and $1000-1200 \mu S \cdot \mathrm{cm}^{-1}$, respectively, and was adjusted weekly. Storage root number and fresh weight were similar regardless of treatments. Plants exposed to prolonged darkness produced $10.5 \%$ and $25 \%$ lower fibrous root fresh and dry mass, respectively, but similar foliage yield and harvest index (HI). 'NCC-58' produced an average of $31 \%$ greater storage root yield than that of ' $\mathrm{TU}-\mathrm{82}-155$ ' but the number of storage roots as well as \% dry matter (\%DM) were similar. 'NCC-58' also produced $31 \%$ greater fibrous root dry weight, whereas ' $\mathrm{TU}-82-155$ ' produced a $44 \%$ greater $\mathrm{HI}$. The significant interaction between prolonged darkness and cultivars for \%DM of the storage roots showed that DM for 'TU-82-155' was $18.4 \%$ under prolonged darkness and $17.9 \%$ in the light. That for 'NCC-58' was $16.4 \%$ under prolonged darkness compared with $19.4 \%$ (14.8\% greater) for plants that were not subjected to prolonged darkness. The evidence that there were no adverse impacts on storage root yield following the exposure to prolonged darkness suggests that the detrimental effects were below the detectable limits for these cultivars in response to the short perturbation in the available light and that sweetpotatoes would be hardy under short-term failure situations.
\end{abstract}

Recently, the National Aeronautics and Space Administration (NASA) laid out its vision for manned missions to Mars in 2030.

Received for publication 20 Jan. 2016. Accepted for publication 11 July 2016 .

Contribution of the George Washington Carver Agricultural Experiment Station, Tuskegee University. This research was supported by funds from the U.S. National Aeronautics and Space Administration (grant no. NCC-9-51 and USDA/CSREES grant no. ALX-SP-1).

${ }^{1}$ Corresponding author. E-mail: mortleyd@mytu. tuskegee.edu.
To achieve this goal, NASA must establish reliable infrastructure including life support and a palatable source of fresh food (NASA 2015). Hydroponically grown sweetpotatoes are potentially a reliable food source for humans on extended space missions. NASA's experience with continuous crop production in closed environments indicates that biological systems can be highly reliable, although failures of mechanical support systems regularly occur. Maintaining adequate food production will be the critical issue following a failure in a bioregenerative life support system since staple crops require in excess of 2 to 3 months to produce edible biomass (Hanford and Ewert, 2001). Perhaps, the most common type of failure is a temporary loss of electrical power and a partial power supply failure might result in low light but not complete darkness. Failures of the power supply system would likely be more common in remote locations such as on Mars, the Moon, or even Antarctica. When failure occurs there will be a time lapse before repairs are affected, which, depending on length of the time lapse, may impact plant responses. There is little data on the decreased performance and the tolerance limits of crop plants exposed to the unique perturbations that occur in closed, controlled environments. Failures are characterized by short-term, acute stress. Cumulative experience in controlled environments indicates that plants are surprisingly resilient to some types of control system failures, but sensitive to other failures, particularly during the reproductive stage of their life cycle (Dougher et al., 2000). Healthy crops produce a predictable, steady supply of oxygen and water. Interruption in crop metabolism alters these outputs and requires changes in the use of stored reserves.

Plants are well adapted to short periods of darkness because they have an 8- to 14-h dark period every night during the growing season. However, plants adapt to their photoperiod and the carbohydrate reserves are typically depleted near the end of the dark period. Thus, with an extended dark period, the respiration rate typically declines from lack of carbohydrates from active photosynthesis. Challa (1976) reported that at the end of the normal dark period, cucumber plants in continuous darkness metabolized structural compounds. Breeze and Elston (1978) reported that as little as a 6-h extension of the dark period caused significant reductions (compared with control plants) in photosynthesis when field bean plants were returned to the light, whereas Yentsch and Reichert (1963) found no signs of adaptation of photosynthesis in algae (Dunaliella euchlora) to lower light intensities after $40 \mathrm{~h}$ of dark exposure. Jones and Nelson (1979) found that root respiration of contrasting tall fescue genotypes decreased significantly after a 48-h dark period but that respiration of shoot meristems continued for the full $48 \mathrm{~h}$ and Costa et al. (1998) found that respiration rates of leaves of broad beans (Vicia faba) decreased steadily during $48 \mathrm{~h}$ of darkness. Robson and Parsons (1981) found that meristematic activity in uniculm barley continued forming new structural mass even during up to $50 \mathrm{~h}$ of darkness. These studies indicate that cell division continued in the absence of carbohydrate supply in at least some plants. Dougher et al. (2000) used canopy gas exchange to evaluate response and recovery of plant canopies of lettuce, spinach, radish, and tomatoes subjected to darkness of up to $14 \mathrm{~d}$. They reported that canopy respiration was reduced to a minimum within 24 to $48 \mathrm{~h}$ of dark treatment. Plants that were subjected to a cold treatment during the dark periods 
Table 1. Main effect of prolonged darkness on storage and fibrous root yield and foliage and $\mathrm{HI}$ of two sweetpotato cultivars in response to $14 \mathrm{~d}$ of darkness. Means are accompanied by \pm SD to provide a better idea of the spread of values within the samples.

\begin{tabular}{|c|c|c|c|c|c|c|}
\hline \multirow[b]{2}{*}{ Source of variation } & \multicolumn{3}{|c|}{ Storage root } & \multirow{2}{*}{$\frac{\text { Fibrous root }}{\text { Dry mass }(\mathrm{g} / \text { plant })}$} & \multirow{2}{*}{$\frac{\text { Foliage }}{\text { Dry mass }\left(\mathrm{g} \cdot \mathrm{m}^{-2}\right)}$} & \multirow[b]{2}{*}{$\mathrm{HI}^{\mathrm{z}}(\%)$} \\
\hline & No. $\left(\mathrm{m}^{2}\right)$ & Dry mass $\left(\mathrm{g} \cdot \mathrm{m}^{-2}\right)$ & Dry matter $(\%)$ & & & \\
\hline Light & $24.5 \pm 2.33$ & $550 \pm 45.8$ & $18.6 \pm 3.1$ & $11.3 \pm 3.8$ & $561.5 \pm 43.3$ & $46.1 \pm 16.3$ \\
\hline Dark & $22.0 \pm 2.23$ & $520 \pm 47.1$ & $17.5 \pm 3.2$ & $8.9 \pm 3.2$ & $520.0 \pm 28.4$ & $48.7 \pm 15.6$ \\
\hline Significance & NS & NS & $*$ & $* *$ & NS & NS \\
\hline
\end{tabular}

${ }^{\mathrm{z}} \mathrm{HI}=$ harvest index (root mass/total plant mass).

Ns, *, *** Nonsignificant or significant at $P=0.05$ or 0.01 , respectively.

recovered quickly when light was restored. In addition, carbon use efficiency (the ratio between the amount of carbon incorporated into dry matter to the amount of carbon fixed in gross photosynthesis) remained the same in all canopies regardless of temperature. In fact, Kubota and Kozai (1994) reported that low temperature storage $\left(5-10^{\circ} \mathrm{C}\right)$ of broccoli seedlings in combination with $2 \mu \mathrm{mol} \cdot \mathrm{m}^{-2} \cdot \mathrm{s}^{-1}$ $P P F$ were important to preserve photosynthetic and regrowth abilities and dry weight of the plantlets. Thus, clearly, a few days of dark stress is not lethal to plants, however, plants do sustain some damage from extended darkness and the extent and rate of recovery has not been examined.

The objective of this research was to determine the impact of prolonged darkness on yield and growth responses of two sweetpotato cultivars grown hydroponically.

\section{Materials and Methods}

A series of experiments were conducted in a randomized complete block design with two replications; the experiments were run five times. Four reach-in growth chambers (Environmental Growth Chambers, Chagrin Falls, $\mathrm{OH})$ were used, and each experiment lasted between 117 and $120 \mathrm{~d}$.

Growth chamber conditions. Growth chambers were set at a constant relative humidity of $70 \% \pm 5 \%$. The $P P F$ was measured weekly with an Apogee LQS-QM Quantum meter (Apogee Instruments, Logan, UT) at the top of the plant canopy $(\approx 20 \mathrm{~cm}$ above the plants). $P P F$ averaged $600 \pm 25$ $\mu \mathrm{mol} \cdot \mathrm{m}^{-2} \cdot \mathrm{s}^{-1}$ and was provided by $400-\mathrm{W}$ metal halide lamps.

Planting and treatments. Four stem cuttings each of breeding clones 'TU-82-155' (now Whatley/Loretan) and 'NCC-58' were transplanted into each of two PVC-1 NFT growth channels $(0.15 \times 0.15 \times 1.2 \mathrm{~m})$ spaced $25 \mathrm{~cm}$ apart. Each vine cutting was held in place by a flat plate assembly (Morris et al., 1989) attached to the sides of the channels by a flexible white and black vinyl covering.

The light, temperature, and relative humidity in the chambers during the first $65 \mathrm{~d}$ were $600 \pm 25 \mu \mathrm{mol} \cdot \mathrm{m}^{-2} \cdot \mathrm{s}^{-1}, 28 / 22{ }^{\circ} \mathrm{C}$ light/ dark, and $70 \% \pm 5 \%$, respectively. At $65 \mathrm{~d}$ after planting, lights were turned off in the treatment chambers and replaced by a single $40-\mathrm{W}$ incandescent lamp hooked to a timer, providing between 7 and $10 \mu \mathrm{mol} \cdot \mathrm{m}^{-2} \cdot \mathrm{s}^{-1}$ $P P F$ for $18 \mathrm{~h}$ daily, and the temperature lowered from $28 / 22{ }^{\circ} \mathrm{C}$ light/dark to a constant $20{ }^{\circ} \mathrm{C}$. Plants remained under these conditions for $14 \mathrm{~d}$, after which the original $P P F$ and temperature cycles were restored.

Nutrient solution. A modified halfstrength Hoagland nutrient solution (Hoagland and Arnon, 1950) was used. The nutrient solution was modified as follows: calcium nitrate was replaced by calcium chloride and reduced to $2 \mathrm{~mm}$, potassium nitrate and magnesium sulfate were reduced from 6 to $3 \mathrm{~mm}$ and 2 to $1 \mathrm{~mm}$ concentrations, respectively. The solution was supplied to the plants in each channel from 91.2-L reservoirs with submersible pumps (Little Giant Pump Co., Oklahoma City, OK). Growth channels were on a $1 \%$ slope to facilitate return of the nutrient solution to the reservoir by gravity flow. The nutrient solution was replenished once per week with deionized water back to volume and a concentrated half-Hoagland's stock added to maintain an EC of 1100-1200 $\mu \mathrm{S} \cdot \mathrm{cm}^{-1} ; \mathrm{pH}$ was adjusted to a range of 5.5 6.0 with $2 \mathrm{M} \mathrm{HCl}$ or $\mathrm{NaOH}$.

Harvest. Plant storage roots and all foliage were harvested $120 \mathrm{~d}$ after planting. Plants were cut at the base and weighed fresh, and after drying for $72 \mathrm{~h}$ at $70{ }^{\circ} \mathrm{C}$. Root samples were separated into three categories based on diameter: fibrous root $(<2 \mathrm{~mm})$, thick roots $(2-5 \mathrm{~mm})$, and storage roots (>5 mm; Wilson and Lowe, 1973). Thick and fibrous roots were combined and are presented as fibrous roots. Storage root fresh weights were determined and a 25-g sample of one root from each plant (3-6 roots harvested per plant) was dried for $72 \mathrm{~h}$ at $70{ }^{\circ} \mathrm{C}$. This dry weight information was used to calculate a fresh-to-dry weight conversion factor to determine storage root dry weight. $\mathrm{HI}$ was calculated as a ratio of total storage root mass to total plant mass $\times 100 \%$. Similarly, percent dry mass [(dry weight/ fresh weight $) \times 100$ ] was calculated for both foliage and fibrous roots.

Experiments were run five times and treatments were switched between chambers to minimize chamber effects. Data were combined by experiments and analyzed by the general linear models procedure (SAS Institute, 2009).

\section{Results and Discussion}

Although the number and fresh production of storage roots were similar regardless of exposure to prolonged darkness, dry mass and $\% \mathrm{DM}$ of storage roots were lower among plants in response to the main effect of prolonged darkness (Table 1). Plants exposed to prolonged darkness produced $25 \%$ lower fibrous root dry mass (Table 1), but similar foliage yield and HI. Thus, the main impact of the exposure of sweetpotato plants to prolonged darkness was to lower dry matter of storage and fibrous roots, suggesting a reduced translocation of assimilates into storage and fibrous roots. In contrast, with the exception of storage and fibrous root dry matter, exposure to prolonged darkness did not adversely affect the number and fresh weight of storage roots or foliage production. The significant interaction between prolonged darkness and cultivars for \%DM of the storage roots (Table 3 ) showed that DM for 'TU-82-155' was $18.4 \%$ under prolonged darkness and $17.9 \%$ in the light, a $2,8 \%$ increase under the prolonged darkness, whereas 'NCC-58' was $16.4 \%$ under prolonged darkness compared with $19.4 \%$ under light, a $15.5 \%$ decrease, under the prolonged darkness. Therefore, storage root dry matter varied with the cultivars used.

'NCC-58' produced an average of 30\% greater storage root yield [31\% fresh weight, (Table 2) and $29 \%$ on a dry mass basis] than that produced by 'TU-82-155' but the number of storage roots as well as \%DM were similar between cultivars. 'NCC-58' also produced $31 \%$ greater fibrous root dry mass than 'TU-82-155' and a marginally greater HI.

Plants that were subjected to prolonged darkness senesced to varying degrees depending on cultivar. Visual observations suggest that the leaves of 'NCC-58' senesced to a greater degree than those of 'TU-82$155^{\prime}$. Preliminary chlorophyll measurements taken on one run of the experiment only with a Minolta SPAD 502 handheld meter (Spectrum Technologies Inc., Aurora, IL) that measures the relative greenness of leaves showed values of $38.7,37.6,28.8$, and 25.9 for 'NCC-58' and 'TU-82-155' in light (control plants) or prolonged darkness, respectively.

Analysis of variance and main effects and interactions between prolonged darkness and cultivars are summarized in Table 3. Prolonged darkness significantly impacted \% $\mathrm{DM}$ of storage roots and fibrous root dry mass, but had no significant effect on any other storage root or foliage variable observed. Cultivars significantly influenced storage root dry mass, fibrous root dry mass, foliage dry mass, and HI, but had no significant effect neither on storage root number, percent dry mass, \%DM, nor percent dry mass of foliage. 
Table 2. Main effect of cultivars on storage and fibrous root yield and foliage and $\mathrm{HI}$ in response to $14 \mathrm{~d}$ of darkness. Means are accompanied by \pm SD to provide a better idea of the spread of values within the samples.

\begin{tabular}{|c|c|c|c|c|c|c|}
\hline \multirow[b]{2}{*}{ Source of variation } & \multicolumn{3}{|c|}{ Storage root } & \multirow{2}{*}{$\frac{\text { Fibrous root }}{\text { Dry mass (g/plant) }}$} & \multirow{2}{*}{$\frac{\text { Foliage }}{\text { Dry mass }\left(\mathrm{g} \cdot \mathrm{m}^{-2}\right)}$} & \multirow[b]{2}{*}{$\mathrm{HI}^{\mathrm{z}}(\%)$} \\
\hline & No. $\left(\mathrm{m}^{2}\right)$ & Dry mass $\left(\mathrm{g} \cdot \mathrm{m}^{-2}\right)$ & Dry matter (\%) & & & \\
\hline NCC-58 & $22.1 \pm 2.31$ & $624.4 \pm 57.8$ & $17.7 \pm 2.7$ & $11.0 \pm 3.2$ & $580.4 \pm 37.6$ & $47.0 \pm 15.4$ \\
\hline TU-82-133 & $23.9 \pm 2.32$ & $460.3 \pm 43.5$ & $18.2 \pm 3.5$ & $8.6 \pm 3.5$ & $483.8 \pm 29.5$ & $43.6 \pm 15.5$ \\
\hline Significance & NS & $* *$ & $*$ & $* *$ & $*$ & NS \\
\hline
\end{tabular}

${ }_{\mathrm{z}}^{\mathrm{HI}}=$ harvest index (root mass/total plant mass).

Ns, *, ${ }^{* *}$ Nonsignificant or significant at $P=0.05$ or 0.01 , respectively.

Table 3. Statistical significance from analysis of variance of prolonged darkness, cultivars, and prolonged darkness $\times$ cultivar reactions for growth responses of two sweetpotato cultivars.

\begin{tabular}{|c|c|c|c|c|c|c|c|}
\hline \multirow[b]{2}{*}{ Source of variation } & \multirow[b]{2}{*}{ df } & \multicolumn{3}{|c|}{ Storage root } & \multirow{2}{*}{$\frac{\text { Fibrous root }}{\text { Dry mass }(\mathrm{g} / \mathrm{plant})}$} & \multirow{2}{*}{$\frac{\text { Foliage }}{\text { Dry mass }\left(\mathrm{g} \cdot \mathrm{m}^{-2}\right)}$} & \multirow[b]{2}{*}{$\mathrm{HI}^{\mathrm{z}}(\%)$} \\
\hline & & No. $\left(m^{2}\right)$ & Dry mass $\left(\mathrm{kg} \cdot \mathrm{m}^{-2}\right)$ & Dry matter (\%) & & & \\
\hline Dark & 1 & NS & NS & $*$ & $* *$ & NS & NS \\
\hline Cultivar (C) & 1 & NS & $* *$ & NS & $* *$ & $*$ & $* *$ \\
\hline Dark $\times C$ & 1 & NS & NS & $* *$ & NS & NS & NS \\
\hline
\end{tabular}

${ }^{\mathrm{z}} \mathrm{HI}=$ harvest index (root mass/total plant mass).

Ns, ${ }^{*}, * *$ Nonsignificant or significant at $P=0.05$ or 0.01 , respectively.

These results show that prolonged darkness significantly influenced only $\% \mathrm{DM}$ and fibrous root dry mass and that there were marginal impacts on storage root yield suggesting that the low $7-10 \mu \mathrm{mol} \cdot \mathrm{m}^{-2} \cdot \mathrm{s}^{-1}$ supplemental light enabled the plants to maintain themselves as well as grow minimally (Chard et al., 2004). This is also evidenced by the fact that predark single leaf photosynthetic levels were restored within $48 \mathrm{~h}$ of the light being restored. Further, Chard et al. (2004) showed that low temperature reduces plant metabolic activities in lettuce, spinach, tomatoes, and radish. Because plant metabolism is greatly reduced, this lessens the plants' need for energy and thus a lower light is needed. They reported that radish and spinach responded as well as control plants when subjected to low temperature and $10 \mu \mathrm{mol} \cdot \mathrm{m}^{-2} \cdot \mathrm{s}^{-1} P P F$, and suggested that this may be related to a reduced light compensation point below $10 \mu \mathrm{mol} \cdot \mathrm{m}^{-2} \cdot \mathrm{s}^{-1}$ after plants adapted to the reduced light levels.

Clearly, the sweetpotato cultivars used in this study exerted a greater influence on growth responses than did exposure to prolonged darkness. 'NCC-58' produced greater storage root and foliage weights than 'TU$82-155$ ', whereas the number of storage roots and $\% \mathrm{DM}$ was greater in 'TU-82-155'. Although not significant, the higher storage root yield in 'NCC-58' than 'TU-82-155' was due in part to larger roots than to the number of roots. 'TU-82-155' had a significantly greater HI than 'NCC-58', suggesting that the distribution of dry matter to storage roots was favored compared with the foliage. High HIs are important in a bioregenerative life support system in which edible production must be maximized and the quantity of plant materials that must be recycled, minimized. These HIs are typical of hydroponically grown sweetpotatoes (Mortley et al., 1996).

Pre- and postdark single-leaf photosynthesis and stomatal conductance rates were measured but they were extremely variable and thus were not included for they did not document any significance between the treatments. Thus, no direct effect of the prolonged dark treatment on the photosynthetic process has been demonstrated in this study, although it is possible that there were some short-term, direct effects on net photosynthetic rates. Generally, we observed that photosynthetic activity was restored within $48 \mathrm{~h}$ after the prolonged darkness ended, suggesting that a short perturbation in the available light did not adversely impact dry matter and overall yield, and thus these cultivars would be hardy under short failure situations.

Although prolonged darkness cannot be good, the evidence that there were no adverse impacts on storage root yield following the exposure to $14 \mathrm{~d}$ of prolonged darkness suggests that the detrimental effects were probably below the detectable limits for these cultivars in response to the short perturbation in the available light given the measurements made in this study, and that sweetpotatoes could be hardy under short-term failure situations.

\section{Literature Cited}

Breeze, V. and J. Elston. 1978. Some effects of temperature and substrate content upon respiration and the carbon balance of field beans (Vica faba L.). Ann. Bot. (Lond.) 42:863-876,

Challa, H. 1976. An analysis of the diurnal course of growth, carbon dioxide exchange, and carbohydrate reserve content of cucumber. Agricultural Research Report. 861. Center for Agrobiological research, Wageningen, the Netherlands.

Chard, J., G. Akula, and B. Bugbee. 2004. Failure analysis research summary: Mitigating the effects of prolonged darkness with low temperature and low light. 10 July 2016. $<\mathrm{http}: / /$ cpl.usu.edu/files/publications/factsheet/pub 6275308.pdf>.

Costa, L.C., J. Morrison, and M. Dennett. 1998. Effects of water stress, temperature, prolonged darkness and pods on photosynthesis and respiration of individual leaves of Vicia faba. Revista Ceres. 45:325-337.
Dougher, T.A.O., J. Frantz, S. Klassen, and B. Bugbee. 2000. Failure analysis: Plant recovery from prolonged darkness. Proc. 4th Intl. Conf. Life Support and Biosphere Sci. p. 26.

Hanford, A.J. and M.K. Ewert. 2001. Advanced life support systems modeling and analysis reference missions document. CTSD-ADV 383: JSC-39502.

Hoagland, D.R. and D.J. Arnon. 1950. The waterculture method for growing plants without soil. California Agr. Exp. Stn. Circ. 347, Univ. California, Berkeley, CA

Jones, R.J. and C.J. Nelson. 1979. Respiration and concentration of water soluble carbohydrate in plant parts of contrasting tall fescue genotypes. Crop Sci. 19:367-372.

Kubota, C. and T. Kozai. 1994. Low temperature storage of transplants at the light compensation point: Air temperature and light intensity for growth suppression and quality preservation. Sci. Hort. 63:193-204.

Morris, C.E., P.A. Loretan, C.K. Bonsai, and W.A. Hill. 1989. Moveable root contact pressure plate assembly for hydroponic system. U.S Patent 4,860,490. 29 Aug. 1989. U.S. Patent Office, Washington, DC

Mortley, D.G., P.A. Loretan, C.K. Bonsai, W.A. Hill, and C.E. Morris. 1996. Growth responses of hydroponically grown sweetpotato tolerant intolerant of a continuous daily light period. HortScience 31:209-212.

NASA. 2015. Journey to Mars: Pioneering next steps in space exploration. NASA Pub. No. 20151008-508

Robson, M.J. and A.J. Parsons. 1981. Respiratory efflux of carbon dioxide from mature and meristematic tissue of uniculm barley during eighty hours of continuous darkness. Ann. Bot. (Lond.) 48:727-731.

SAS Institute. 2009. SAS user's guide. Statistics, version 9.2 edition. SAS Institute, Cary, NC.

Wilson, L.A. and S.B. Lowe. 1973. Quantitative morphogenesis of root types in the sweetpotato [Ipomoea batatas (L.) Lam] root system during growth from stem cuttings. Trop. Agr. 50:343345 .

Yentsch, C.S. and C.A. Reichert. 1963. Effects of prolonged darkness on photosynthesis, respiration and chlorophyll in the marine flagellate, Dunaliella euchlora. Limnol. Oceanogr. 8: 338-342. 